\title{
The PDGF pathway in breast cancer is linked to tumour aggressiveness, triple-negative subtype and early recurrence
}

\author{
Sara Jansson $^{1}$ (D) $\cdot$ Kristina Aaltonen ${ }^{1} \cdot$ Pär-Ola Bendahl ${ }^{1} \cdot$ Anna-Karin Falck ${ }^{2} \cdot$ Maria Karlsson $^{3} \cdot$ Kristian Pietras $^{4}$. \\ Lisa Rydén ${ }^{3,5}$
}

Received: 23 August 2017 / Accepted: 5 January 2018 / Published online: 29 January 2018

(c) The Author(s) 2018. This article is an open access publication

\begin{abstract}
Purpose The platelet-derived growth factor (PDGF) signalling pathway is often dysregulated in cancer and PDGF-receptor expression has been linked to unfavourable prognostic factors in breast cancer (e.g. ER negativity, high Ki67 and high grade). This study aimed to evaluate the expression of PDGFR $\alpha$, PDGFR $\beta$ and ligand PDGF-CC in breast cancer in relation to molecular subtypes and prognosis.

Methods Protein expression of tumour and/or stromal cell PDGFR $\alpha$, PDGFR $\beta$ and PDGF-CC was evaluated in primary tumours $(N=489)$, synchronous lymph node metastases $(N=135)$ and asynchronous recurrences $(N=39)$ using immunohistochemistry in a prospectively maintained cohort of primary breast cancer patients included during 1999-2003. Distant recurrence-free interval (DRFi) was the primary end-point.

Results High expression of all investigated PDGF family members correlated to increasing Nottingham histopathological grade and high Ki67. Tumour cells displayed high expression of PDGFR $\alpha$ in 20\%, and PDGF-CC in 21\% of primary tumours, which correlated with the triple-negative subtype (TNBC). Patients with high PDGF-CC had inferior prognosis $(P=0.04)$ in terms of 5-year DRFi, whereas PDGFR $\alpha$ was up-regulated in lymph node metastasis and recurrences compared to primary tumours. High primary tumour PDGFR $\alpha$ was associated with increased risk of central nervous system (CNS) recurrence.

Conclusions High PDGFR $\alpha$ and PDGF-CC expression were linked to breast cancer with an aggressive biological phenotype, e.g. the TNBC subtype, and high PDGF-CC increased the risk of 5-year distant recurrence. Tumour cell PDGFR $\alpha$ was significantly up-regulated in lymph node metastases and asynchronous recurrences. Our findings support an active role of the PDGF signalling pathway in tumour progression.
\end{abstract}

Keywords Breast cancer $\cdot$ Triple-negative breast cancer $\cdot$ Platelet-derived growth factor receptor $\cdot$ Platelet-derived growth factor-CC $\cdot$ Tyrosine kinase receptor $\cdot$ Targeted therapy

\section{Introduction}

Electronic supplementary material The online version of this article (https://doi.org/10.1007/s10549-018-4664-7) contains supplementary material, which is available to authorized users.

Sara Jansson

sara.jansson@med.lu.se

1 Division of Oncology and Pathology (Clinical Sciences), Department of Clinical Sciences Lund, Lund University, Medicon Village 404:C2, Scheelev. 2, SE-223 81 Lund, Sweden

2 Department of Surgery, Helsingborg Hospital, SE-251 87 Helsingborg, Sweden
The platelet-derived growth factor receptor (PDGFR) pathway is a signalling network of importance for the normal development of cells of mesenchymal origin. The PDGF signalling network consists of two tyrosine kinase receptors,

3 Division of Surgery, Department of Clinical Sciences Lund, Skåne University Hospital, Lund University, SE-221 85 Lund, Sweden

4 Division of Translational Cancer Research, Department of Laboratory Medicine, Medicon Village, SE-223 81 Lund, Sweden

5 Department of Surgery and Gastroenterology, Skåne University Hospital, SE-205 02 Malmö, Sweden 
PDGFR alpha (PDGFR $\alpha$ ) and PDGFR beta (PDGFR $\beta$ ), and five ligands PDGF-AA, PDGF-BB, PDGF-AB, PDGF-CC and PDGF-DD, which are formed from four gene products (PDGF A, B, C and D) [1]. Autocrine stimulation of the pathway is frequently observed in various neoplasms, such as gliomas [2], gastro-intestinal stromal tumours (GISTs) [3] and chronic myelomonocytic leukaemia [4]. In addition, dysregulation of paracrine PDGFR signalling can cause extracellular matrix remodelling in a tumour-promoting way to facilitate migration, invasion, angiogenesis and possibly also lymph angiogenesis [5, 6].

In breast cancer, most studies of the PDGF signalling pathway examine the expression of PDGFR $\alpha$ and PDGFR $\beta$. PDGFR $\alpha$ expression has been described both in stroma and in tumour cells. High tumour cell PDGFR $\alpha$ expression has been linked to lymph node metastasis, human epidermal growth factor receptor 2 (HER2) positivity [7], high histologic grade, oestrogen receptor (ER) negativity, progesterone receptor $(\mathrm{PR})$ negativity and the triple-negative breast cancer subtype (TNBC) $[8,9]$. High stromal PDGFR $\alpha$ has been linked to HER2 positivity and high Ki67 [9]. PDGFR $\beta$ expression in breast cancer has only been reported in stroma and high expression has been associated to HER2 positivity, high Ki67 [9], high histopathologic grade, ER negativity and shorter survival [10].

The PDGF-CC ligand was discovered towards the end of the 1990s and it has been shown to be involved in tumour growth by paracrine signalling through PDGFR $\alpha$ in malignant melanoma and cervical carcinoma $[11,12]$. However, to date little is known about the role of PDGF-CC in breast cancer. We have recently shown that tumour cell-derived PDGF-CC acts on neighbouring tumour stromal cells in mouse models, and we proposed that the PDGF signalling pathway is a regulator of breast tumour subtype with high PDGF-CC driving breast tumours towards a more basal-like phenotype [13]. Basal-like breast cancer (BLBC) is a subtype of breast cancer defined by gene expression profiling and it is characterised by the expression of genes related to basal epithelial cells such as keratin 5, keratin 17 , integrin- $\beta 4$ and laminin [14]. BLBC largely overlaps with the molecular surrogate breast cancer subtype TNBC, which is defined by immunohistochemistry as being negative for the ER, PR and HER2 receptors [15]. Patients with TNBC are generally younger, have larger tumours with high grade at diagnosis and are more frequently BRCA-mutation carriers [16]. They also have a poor prognosis and no targeted therapies are hitherto available. It is thus particularly desirable to find targetable tumour-driving pathways within TNBC [17]. The PDGF signalling network holds promise of such a pathway, in TNBC in particular and in breast cancer in general.

The aim of the present study was to explore the expression of PDGFR $\alpha$, PDGFR $\beta$ and ligand PDGF-CC in breast cancer to elucidate if these proteins are associated with molecular surrogate subtypes, type of metastatic location and prognosis in breast cancer. A secondary aim was to explore the relation to tumour progression by investigating changes in protein expression between primary tumour, synchronous lymph node metastases and asynchronous recurrences.

\section{Materials and methods}

\section{Patients}

The patient cohort in this study was originally assembled for a prospective observational study with the aim of evaluating the presence and prognostic value of disseminated tumour cells in the bone marrow of patients diagnosed with primary breast cancer [18]. The study was approved by the Lund University ethics committee, and a written informed consent was obtained from all the included patients (LU69909, LU75-02). Further information about the patient cohort has been published elsewhere [8, 18-20]. Detailed information on routine prognostic factors, St Gallen molecular subtype and clinical follow-up data were assembled for all the patients as described by Falck et al. [19, 20]. The latest review of patient charts to evaluate recurrence status was performed in 2015 and all events until November 2015 were recorded. A recurrence was defined as a radiologic and/or biopsy verified breast cancer-related event. Recurrences within the breast, chest wall, axilla or loco-regional lymph nodes were considered as loco-regional, whereas recurrences in distant organs [e.g. liver, lung and central nervous system (CNS)] were considered as distant. Data on breast cancer-related death were retrieved from the Swedish Register of Causes of Death (Central Statistics Office). We followed the REporting recommendations for tumour MARKer prognostic studies (REMARK) criteria [21].

\section{Tissue microarray and immunohistochemistry}

Tissue microarrays (TMAs) of formalin-fixed, paraffinembedded tumour tissue samples were retrieved from the Department of Pathology, in Lund and Helsingborg, Sweden. TMAs consisted of tissue core biopsies of $1.0 \mathrm{~mm}$ in diameter taken from representative areas of invasive breast cancer using a tissue array machine (TMArrayer ${ }^{\mathrm{TM}}$, Pathology Devices, Inc.). Two core biopsies were taken from each tumour sample. TMA sections between 3 and $4 \mu \mathrm{m}$ thick were transferred to glass slides (Menzel Super frost plus, Thermo Scientific, Germany), dried at room temperature and baked in a heat chamber for $2 \mathrm{~h}$ at $60{ }^{\circ} \mathrm{C}$. After deparaffinisation and antigen retrieval, immunohistochemistry (IHC) staining was performed using Autostainer Plus 
(Dako Denmark A/S, Glostrup, Denmark). The following antibodies and dilutions were used: PDGFR $\alpha$ (\#3164 Cell Signaling Technology, Inc., Danvers, MA, USA, 1:100), PDGFR $\beta$ (\#3169 from Cell Signaling Technology, Inc., Danvers, MA, USA, 1:100) and PDGF-CC (Karolinska Institute, Stockholm, Sweden, 1:2000). A Rabbit Link K8009 (Dako Denmark A/S, Glostrup, Denmark) was used to amplify the signal of the primary PDGFR $\alpha$ antibody. All slides were counterstained with Mayer's Haematoxylin applied for $2 \mathrm{~min}$ and a visualization kit K801021-2 (Dako Denmark A/S, Glostrup, Denmark) was used for all stainings.

PDGFR $\alpha$ was evaluated both in tumour cells and stromal cells, whereas PDGFR $\beta$ was only evaluated in stromal cells, as no staining was found in tumour cells, and PDGF-CC only in tumour cells. Tumour cell PDGFR $\alpha$ assessment was performed using a histoscore from 0 to 12 as previously described [8].

Stromal PDGFR $\alpha$, PDGFR $\beta$ and tumour cell PDGF-CC were assessed by a clinical pathologist (DG) and scored for staining intensity $0-3(0=$ negative, $1=$ weak, $2=$ intermediate and $3=$ strong). A tumour was considered positive (high expression) when the intensity was 3 and negative (intermediate, low or absent expression) if the intensity was 0-2 [10].

For both tumour cell and stromal cell staining, only TMA core biopsies with $>100$ invasive tumour cells were included. In the statistical analyses, the highest value for the two cores was used. PDGFR $\alpha$, PDGFR $\beta$ and PDGF$\mathrm{CC}$ expression was analysed both as ordinal variables, and dichotomized into positive (high expression) versus negative (intermediate, low or absent expression) as described above. Staining procedures and assessments of ER, PR, HER2, EGFR and CK5/6 have been described in detail elsewhere [19].

\section{Statistical analysis}

The association between biomarker expression and different patient and tumour characteristics was analysed with binary logistic regression. Fisher's exact test was used to explore any association between primary tumour PDGF expression (positive or negative) and site of recurrence. Comparison of biomarker status between primary tumours, lymph node metastases and distant recurrences was performed using the McNemar test. The Jonckheere Terpstra test was used to test for ordered differences between receptor and ligand status. To evaluate survival effect, Kaplan-Meier survival curves and log rank test or log rank linear trends for factor levels were used. Hazard ratios (HR) were calculated by Cox regression and multivariable analyses were adjusted for age, tumour size, synchronous lymph node metastasis, Nottingham histological grade (NHG) and subtype according to St Gallen 2013. Distant recurrence-free interval (DRFi) was used as end-point. DRFi was defined as the time from surgery of the primary tumour until radiologic and/or biopsy verified distant recurrence or breast cancer-related death. Patients without event were censored at last medical follow-up visit. DRFi was stratified into three time intervals ( $0-5$ years, $>5-10$ years and $>10$ years) which were analysed separately to explore short- and long-term effects of the biomarkers, respectively. The results from these post hoc analyses should be interpreted cautiously. Statistical calculations were performed using IBM SPSS Statistics (version 24.0, IBM, Armonk, NY, USA). All $P$ values presented are two-sided and $P$ values $<0.05$ were considered statistically significant.

\section{Results}

\section{Patient and tumour characteristics}

A total of 550 patients were included in the present study. Primary tumours from 473 patients $(86 \%)$ had a known St Gallen subtype according to guidelines from 2013 [15] (Luminal A $=193$; Luminal B HER2- = 153; Luminal B HER $2+=79$; HER $2+=15$; triple-negative breast cancer $[\mathrm{TNBC}]=33$ ). Further data on patient and tumour characteristics are provided in Table 1. Median age at diagnosis was 57.8 years (26-91 years) and median follow-up time for patients alive without any event was 13.7 years (1.0-16.6 years). Synchronous lymph node metastases were present in 215 patients and asynchronous recurrence was recorded in 153 patients. Amongst the asynchronous recurrences, 76 patients had a local, loco-regional or contralateral event and 77 patients developed distant recurrence. Eightynine patients experienced early recurrence (within 5 years of primary breast cancer diagnosis). Due to limited remaining tissue material, synchronous lymph node metastasis and asynchronous recurrences were only evaluable in 135 and 39 patients, respectively (Fig. 1).

\section{Patient and tumour characteristics in relation to primary tumour expression of PDGFRa, PDGFR $\beta$ and PDGF-CC}

Examples of IHC staining are given in Fig. 2. Tumour cells showed high expression of PDGFR $\alpha$ in 100 (20\%) and PDGF-CC in 103 (21\%) of the evaluated primary tumours. Stromal cells showed high expression of PDGFR $\alpha$ in 243 (50\%) and PDGFR $\beta$ in 128 (27\%) of the evaluated primary tumours. High expression of all investigated PDGF family members correlated to increasing NHG and high Ki67, and also to different degrees to TNBC, expression of cytokeratin $5 / 6(\mathrm{CK} 5 / 6+)$, young age ( $<50$ years), large tumour size, ER-, PR- and EGFR+ (Table 1). 
Table 1 Odds ratio (OR) of biomarker expression in relation to tumour and patient characteristics

\begin{tabular}{|c|c|c|c|c|c|}
\hline Biomarker expression & $\begin{array}{l}\text { All } \\
\text { patients } \\
N=550 \\
N(\%)\end{array}$ & $\begin{array}{l}\text { PDGFR } \alpha \text { in tumour cells } \\
\text { OR }(95 \% \mathrm{CI})\end{array}$ & $\begin{array}{l}\text { PDGFR } \alpha \text { in stroma } \\
\text { OR }(95 \% \mathrm{CI})\end{array}$ & $\begin{array}{l}\text { PDGFR } \beta \text { in stroma } \\
\text { OR }(95 \% \mathrm{CI})\end{array}$ & $\begin{array}{l}\text { PDGF-CC in tumour cells } \\
\text { OR }(95 \% \mathrm{CI})\end{array}$ \\
\hline \multicolumn{6}{|l|}{ Age (median) } \\
\hline$<50$ & $110(20)$ & 1.0 & 1.0 & 1.0 & 1.0 \\
\hline$\geq 50$ & $440(80)$ & $0.80(0.47-1.35)$ & $0.46(0.29-0.73)^{*}$ & $0.56(0.35-0.89)^{*}$ & $0.33(0.21-0.55)^{*}$ \\
\hline \multicolumn{6}{|l|}{ T-size } \\
\hline$\leq 20 \mathrm{~mm}$ & $366(67)$ & 1.0 & 1.0 & 1.0 & 1.0 \\
\hline$>20 \mathrm{~mm}$ & $179(33)$ & $0.86(0.54-1.38)$ & $0.97(0.66-1.40)$ & $1.08(0.71-1.66)$ & $2.14(1.37-3.35)^{*}$ \\
\hline \multicolumn{6}{|l|}{ Node status } \\
\hline No & $319(60)$ & 1.0 & 1.0 & 1.0 & 1.0 \\
\hline $\mathrm{N}+$ & $215(40)$ & $0.67(0.42-1.06)$ & $1.23(0.85-1.77)$ & $1.21(0.80-1.82)$ & $1.10(0.70-1.71)$ \\
\hline \multicolumn{6}{|l|}{ NHG } \\
\hline I & $118(22)$ & 1.0 & 1.0 & 1.0 & 1.0 \\
\hline II & $287(54)$ & $0.99(0.54-1.80)$ & $1.08(0.68-1.72)$ & $1.41(0.80-2.51)$ & $1.26(0.63-2.54)$ \\
\hline III & $129(24)$ & $1.94(1.03-3.69)^{*}$ & $3.01(1.74-5.21)^{*}$ & $2.55(1.37-4.73)^{*}$ & $7.72(2.83-11.52)^{*}$ \\
\hline \multicolumn{6}{|l|}{ Ki67 } \\
\hline Low $(\leq 20)$ & $335(67)$ & 1.0 & 1.0 & 1.0 & 1.0 \\
\hline High $(>20)$ & $165(33)$ & $3.47(2.20-5.48)^{*}$ & $1.82(1.23-2.67)^{*}$ & $2.12(1.39-3.23)^{*}$ & $5.13(3.21-8.20)^{*}$ \\
\hline \multicolumn{6}{|l|}{ St Gallen subtype } \\
\hline Luminal A & $193(41)$ & 1.0 & 1.0 & 1.0 & 1.0 \\
\hline Luminal B HER2- & $153(32)$ & $1.74(1.01-3.00)^{*}$ & $1.07(0.70-1.66)$ & $1.03(0.63-1.70)$ & $3.60(1.84-7.04) *$ \\
\hline Luminal B HER2+ & 79 (17) & $1.38(0.70-2.71)$ & $1.58(0.92-2.71)$ & $1.40(0.78-2.52)$ & $3.34(1.55-7.19)^{*}$ \\
\hline HER2-type & $15(3)$ & $0.90(0.19-4.25)$ & $6.68(1.44-30.97)^{*}$ & $0.84(0.22-3.19)$ & $10.10(2.99-34.19)^{*}$ \\
\hline TNBC & $33(7)$ & $2.71(1.19-6.18)^{*}$ & $1.65(0.78-3.48)$ & $0.94(0.39-2.23)$ & $30.12(11.72-77.43)^{*}$ \\
\hline \multicolumn{6}{|l|}{ ER } \\
\hline Neg & $57(11)$ & 1.0 & 1.0 & 1.0 & 1.0 \\
\hline Pos & $449(89)$ & $0.82(0.42-1.58)$ & $0.41(0.22-0.75)^{*}$ & $1.06(0.56-2.03)$ & $0.10(0.06-0.19) *$ \\
\hline \multicolumn{6}{|l|}{ PR } \\
\hline $\mathrm{Neg}$ & $108(23)$ & 1.0 & 1.0 & 1.0 & 1.0 \\
\hline Pos & $367(77)$ & $0.77(0.46-1.30)$ & $0.75(0.49-1.16)$ & $0.93(0.57-1.51)$ & $0.18(0.11-0.29)^{*}$ \\
\hline \multicolumn{6}{|l|}{ EGFR } \\
\hline Neg & $419(83)$ & 1.0 & 1.0 & 1.0 & 1.0 \\
\hline Pos & $84(17)$ & $1.25(0.71-2.21)$ & $1.98(1.21-3.22)^{*}$ & $1.49(0.89-2.49)$ & $5.97(3.56-10.01)^{*}$ \\
\hline \multicolumn{6}{|l|}{ CK5/6 } \\
\hline $\mathrm{Neg}$ & $378(75)$ & 1.0 & 1.0 & 1.0 & 1.0 \\
\hline Pos & $124(25)$ & $1.65(1.02-2.68)^{*}$ & $1.31(0.87-2.00)$ & $1.00(0.62-1.58)$ & $3.67(2.30-5.87)^{*}$ \\
\hline \multicolumn{6}{|l|}{ HER2 } \\
\hline $\mathrm{Neg}$ & $440(88)$ & 1.0 & 1.0 & 1.0 & 1.0 \\
\hline Pos & $62(12)$ & $0.86(0.49-1.51)$ & $1.90(1.20-3.00)^{*}$ & $1.42(0.88-2.32)$ & $1.52(0.91-2.53)$ \\
\hline \multicolumn{6}{|l|}{ Recurrence } \\
\hline No & $398(72)$ & 1.0 & 1.0 & 1.0 & 1.0 \\
\hline Loco-regional or contralateral & $75(14)$ & $1.22(0.65-2.31)$ & $1.80(1.03-3.16)^{*}$ & $1.10(0.61-1.96)$ & $2.19(1.23-3.91)^{*}$ \\
\hline Distant & $77(14)$ & $1.08(0.58-2.02)$ & $0.76(0.40-1.46)$ & $0.82(0.45-1.50)$ & $1.01(0.53-1.92)$ \\
\hline \multicolumn{6}{|l|}{ Metastatic location } \\
\hline Bone & $28(36)$ & 1.0 & 1.0 & 1.0 & 1.0 \\
\hline Visceral & $43(56)$ & $1.22(0.32-4.65)$ & $0.52(0.19-1.42)$ & $0.84(0.27-2.64)$ & $0.74(0.20-2.74)$ \\
\hline CNS & $6(8)$ & $11.50(1.55-85.15)^{*}$ & $0.54(0.08-3.45)$ & 0 & $4.2(0.65-27.36)$ \\
\hline
\end{tabular}

$N H G$ Nottingham histological grade, $E R$ oestrogen receptor, $P R$ progesterone receptor, $E G F R$ epidermal growth factor receptor; $C K 5 / 6$ cytokeratin 5/6, HER2 human epidermal growth factor receptor 2, TNBC triple-negative breast cancer, $C N S$ central nervous system

*Significant at the 0.05 level 


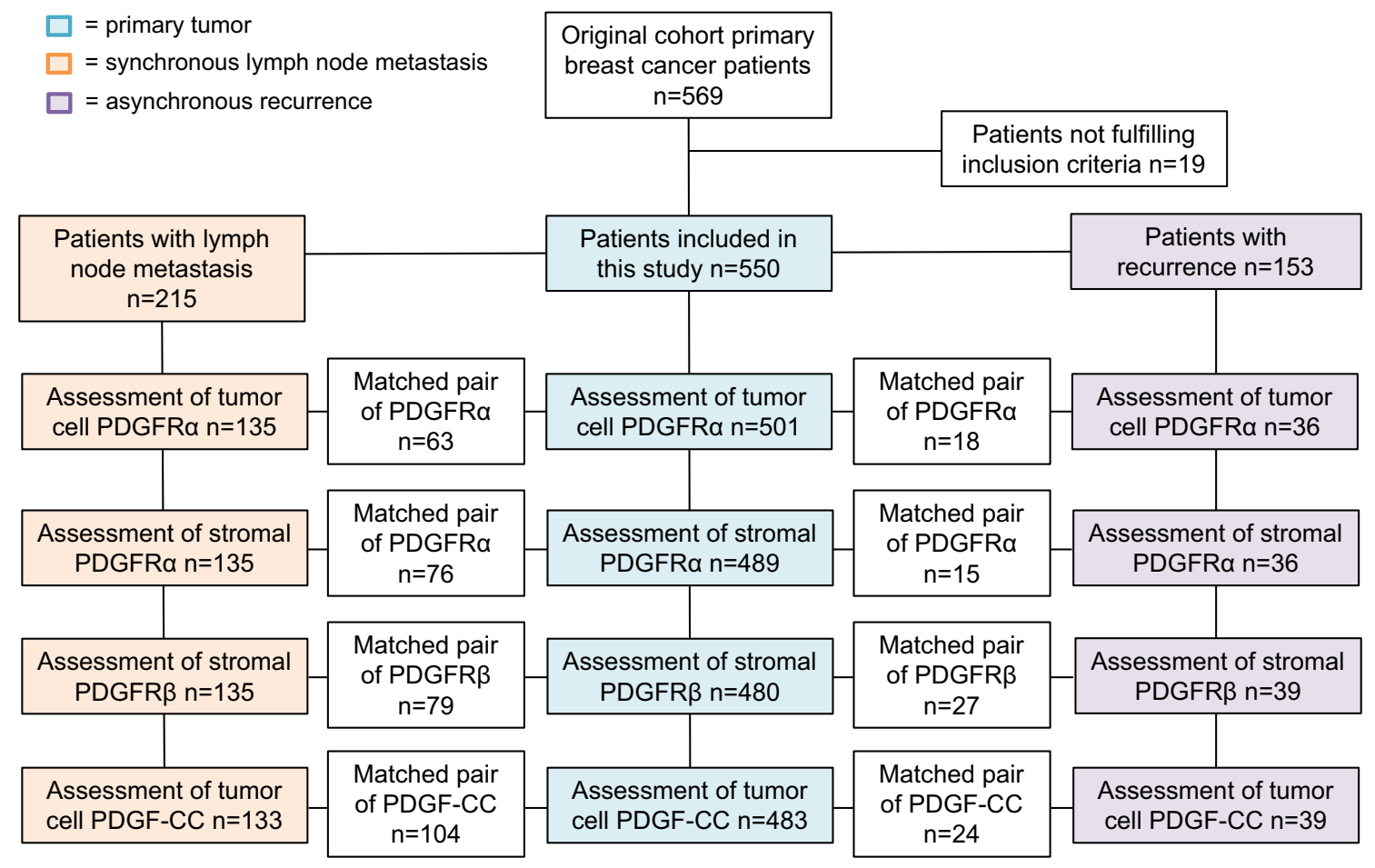

Fig. 1 Flowchart of patient cohort and biomarker expression in primary tumour, synchronous lymph node metastases and asynchronous recurrences. Due to limited remaining tissue material, synchronous lymph node metastasis and asynchronous recurrences were only evaluable in 135 and 39 patients, respectively. Boxes are inserted into

The 77 patients that developed distant recurrence were divided into three groups based on the primary distant metastatic site; bone only (28 patients), visceral (43 patients) and CNS (6 patients) (Fig. 3a). If several primary metastatic locations were present, the worst was recorded in the following order: 1: CNS, 2: visceral and 3: bone. The relation between primary tumour PDGF expression and site of distant recurrence is given in Fig. 3b. Recurrence within CNS was more common in patients with high primary tumour cell PDGFR $\alpha$ expression, 4/15 (27\%) versus 2/58 (3\%), $P=0.01$.

\section{Biomarker expression and tumour progression}

Figure 1 presents an overview of the PDGF assessments at different locations. Tumour cells showed high expression of PDGFR $\alpha$ in $76(56 \%)$ and PDGF-CC in $29(22 \%)$ of synchronous lymph node metastasis, whereas stromal cells showed high expression of PDGFR $\alpha$ in $68(50 \%)$ and PDGFR $\beta$ in 46 (34\%). In asynchronous recurrences, tumour cells showed high expression of PDGFR $\alpha$ in 23 (64\%) and PDGF-CC in 8 (21\%). Stromal cells showed high expression of PDGFR $\alpha$ in $11(31 \%)$ and PDGFR $\beta$ in $2(5 \%)$ of evaluated asynchronous recurrences. the flowchart displaying information on matched pairs, i.e. numbers of primary tumours and nodes, and primary tumours and recurrences displaying identical scoring of each marker, respectively (positivepositive or negative-negative)

A substantial number of tumours displayed a shift in biomarker expression from primary tumour to lymph node metastases and recurrences. The shift was significantly skewed for PDGFR $\alpha$ expression in tumour cells, which was up-regulated in lymph node metastases and recurrences, and for stromal PDGFR $\beta$ expression, which was down-regulated in recurrences (Table 2 ).

\section{Concomitant expression of ligand PDGF-CC and the PDGF receptors}

In total, 80 primary tumours (18\%) had concomitant high expression of ligand PDGF-CC in tumour cells and at least one of the PDGF receptors in tumour and/or stromal cells. Forty-one ( $8 \%$ ) of primary tumours displayed a high expression of both PDGFR $\alpha$ in tumour cells and PDGFCC, $63(13 \%)$ of PDGFR $\alpha$ in stromal cells and PDGF-CC, and 36 (7\%) of PDGFR $\beta$ in stromal cells and PDGF-CC. Only 2 tumours had high expression of PDGFR $\beta$ and PDGF-CC in combination with absent or low expression of PDGFR $\alpha$ (in both stromal and tumour cells), whereas 42 tumours had high expression of PDGFR $\alpha$ (in stromal and/or tumour cells) and PDGF-CC in combination with low PDGFR $\beta$ (Supplementary Table S1). 


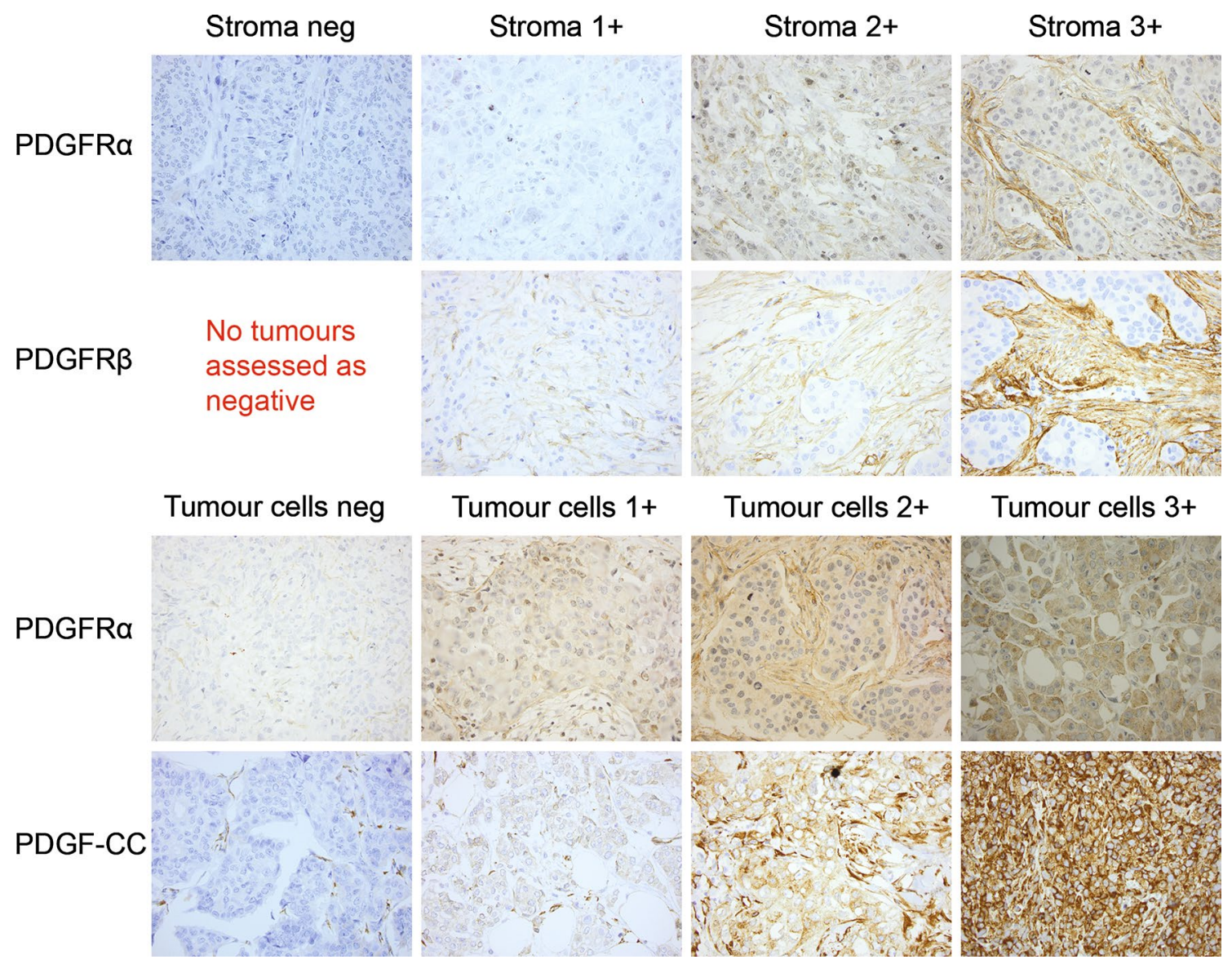

Fig. 2 Examples of IHC stainings for the members of the PDGF family. PDGFR $\alpha$ in stromal cells (1st row), PDGFR $\beta$ in stromal cells (2nd row), PDGFR $\alpha$ in tumour cells ( 3 rd row) and PDGF-CC in tumour cells (4th row). Original magnification $\times 40$

Forty-nine (10\%) of primary tumours had high expression of PDGFR $\alpha$ in both stromal and tumour cells, whereas $182(37 \%)$ had low or absent expression of this receptor in both stromal and tumour cells.

To further explore the relation between PDGF-CC and the PDGF receptors, we analysed receptor-ligand combinations using non-dichotomized data. This showed a significant association between increasing expression of both PDGFR $\alpha$ and PDGFR $\beta$, and increasing PDGF-CC levels $(P<0.001$ for tumour and stromal cell PDGFR $\alpha$ expression, $P=0.004$ for stromal cell PDGFR $\beta$ expression, Supplementary Fig. S1a-c.).

All combinations of concomitant high expression of ligand PDGF-CC and either of the PDGF receptors were significantly associated with young age, increasing NHG, high Ki67, TNBC, ER-, PR-, CK5/6+ and EGFR+ (Supplementary Table S2). No significant difference was seen in survival for patients carrying tumours with concomitant high receptor and ligand expression (data not shown).

\section{Primary tumour biomarker expression and prognosis}

One hundred and eleven patients (20\%) experienced distant breast cancer recurrence and/or breast cancer-related death and contributed to events in DRFi. Kaplan-Meier and log rank test showed a significant difference in DRFi over different breast cancer subtypes (Fig. 4a, $P<0.001$ ). As expected, Luminal A had the best prognosis and TNBC the worst.

For patients with primary tumours positive versus negative for PDGF-CC, no significant difference in DRFi was found over the complete follow-up time (Fig. $4 \mathrm{~b}, P=0.30$ ). However, the survival curve indicated a prognostic effect over the first few years following breast cancer diagnosis. We thus divided the follow-up time into three intervals, $0-5$ years, $>5-10$ years and $>10$ years. This revealed a significant increased risk of early breast cancer event (recurrence or breast cancer-related death within 5 years of primary diagnosis) in the group of patients with tumours 
Fig. 3 a Overview of primary metastatic site at time of recurrence. b Relation between primary tumour PDGF expression (receptors $\alpha, \beta$ or ligand -CC) and site of distant recurrence a

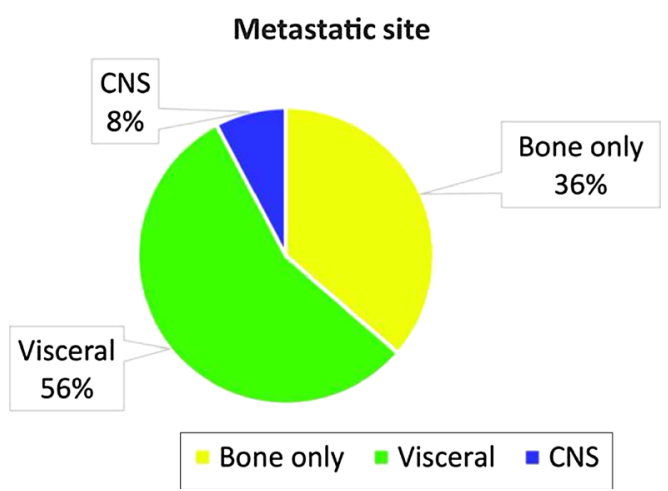

b

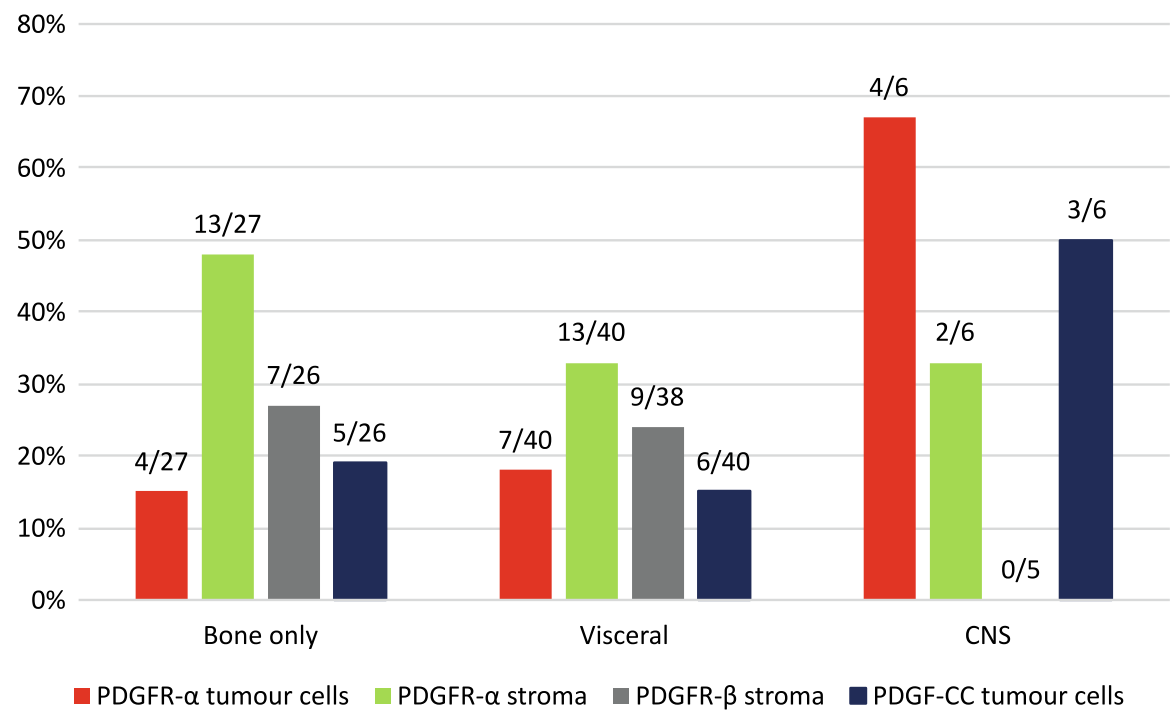

Table 2 Biomarker concordance and discordance in matched pairs of primary tumours versus corresponding lymph node metastases and asynchronous recurrences

\begin{tabular}{|c|c|c|c|c|c|c|c|c|}
\hline \multirow{2}{*}{$\begin{array}{l}\text { Biomarker expression } \\
\text { Location }\end{array}$} & \multicolumn{2}{|c|}{$\begin{array}{l}\text { PDGFR } \alpha \text { in tumour } \\
\text { cells }\end{array}$} & \multicolumn{2}{|c|}{$\begin{array}{l}\text { PDGFR } \alpha \text { in } \\
\text { stroma }\end{array}$} & \multicolumn{2}{|c|}{$\begin{array}{l}\text { PDGFR } \beta \text { in } \\
\text { stroma }\end{array}$} & \multicolumn{2}{|c|}{$\begin{array}{l}\text { PDGF-CC in } \\
\text { tumour cells }\end{array}$} \\
\hline & $N(\%)$ & $P^{*}$ & $N(\%)$ & $P^{*}$ & $N(\%)$ & $P^{*}$ & $N(\%)$ & $P^{*}$ \\
\hline \multicolumn{9}{|l|}{ PT versus $N$} \\
\hline PT pos/N pos & $11(8)$ & $<0.001$ & $41(32)$ & 0.7 & $17(14)$ & 0.4 & $18(14)$ & 0.2 \\
\hline PT pos/N neg & $6(5)$ & & $29(22)$ & & $20(26)$ & & $16(13)$ & \\
\hline PT neg/N pos & $61(47)$ & & $25(19)$ & & $27(21)$ & & $8(6)$ & \\
\hline PT neg/N neg & $52(40)$ & & $35(27)$ & & $62(49)$ & & $86(67)$ & \\
\hline Total & $130(100)$ & & $130(100)$ & & $126(100)$ & & $128(100)$ & \\
\hline \multicolumn{9}{|l|}{ PT versus $R$} \\
\hline PT pos/R pos & $9(26)$ & 0.02 & $2(6)$ & 0.6 & $0(0)$ & 0.02 & $6(17)$ & 0.07 \\
\hline PT pos/R neg & $3(9)$ & & $11(32)$ & & $9(24)$ & & $9(26)$ & \\
\hline PT neg/R pos & $13(38)$ & & $8(24)$ & & $1(3)$ & & $2(6)$ & \\
\hline PT neg/R neg & $9(26)$ & & $13(38)$ & & $27(73)$ & & $18(51)$ & \\
\hline Total & $34(100)$ & & $34(100)$ & & $37(100)$ & & $35(100)$ & \\
\hline
\end{tabular}

$P T$ primary tumour, $N$ lymph node metastasis, $R$ recurrence, neg negative, pos positive

*McNemar test 


\section{a}

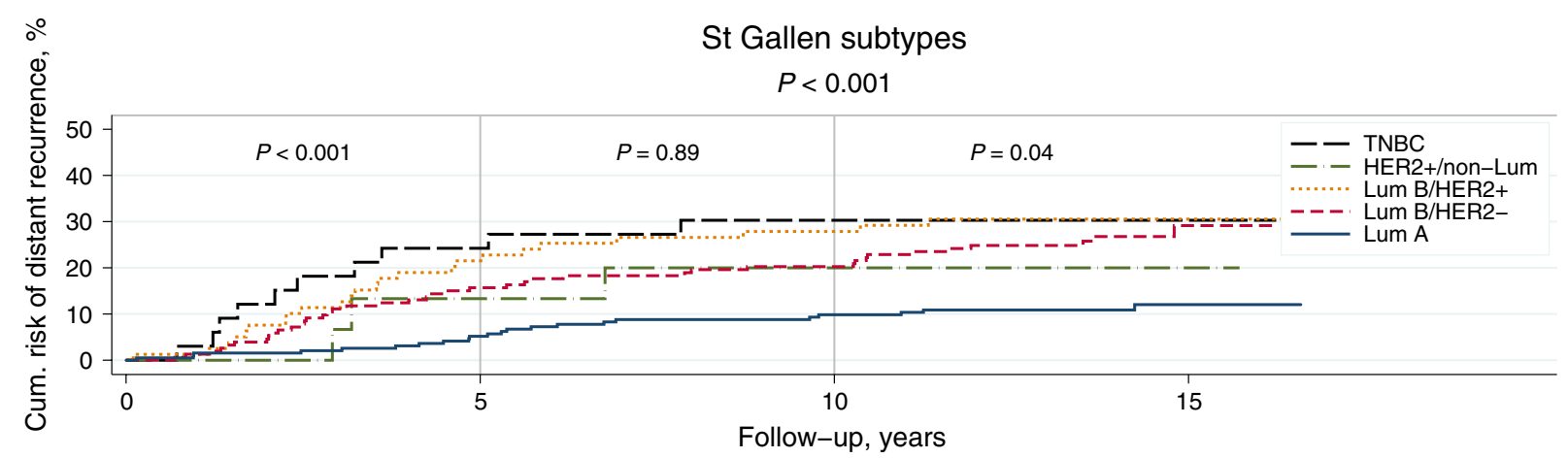

\begin{tabular}{lcccc}
\multicolumn{1}{c}{ At risk } & & & 19 & 3 \\
TNBC & 33 & 23 & 12 & 3 \\
HER2+/non-Lum & 15 & 13 & 52 & 8 \\
Lum B/HER2+ & 79 & 62 & 107 & 19 \\
Lum B/HER2- & 153 & 125 & 156 & 35 \\
Lum A & 193 & 178 &
\end{tabular}

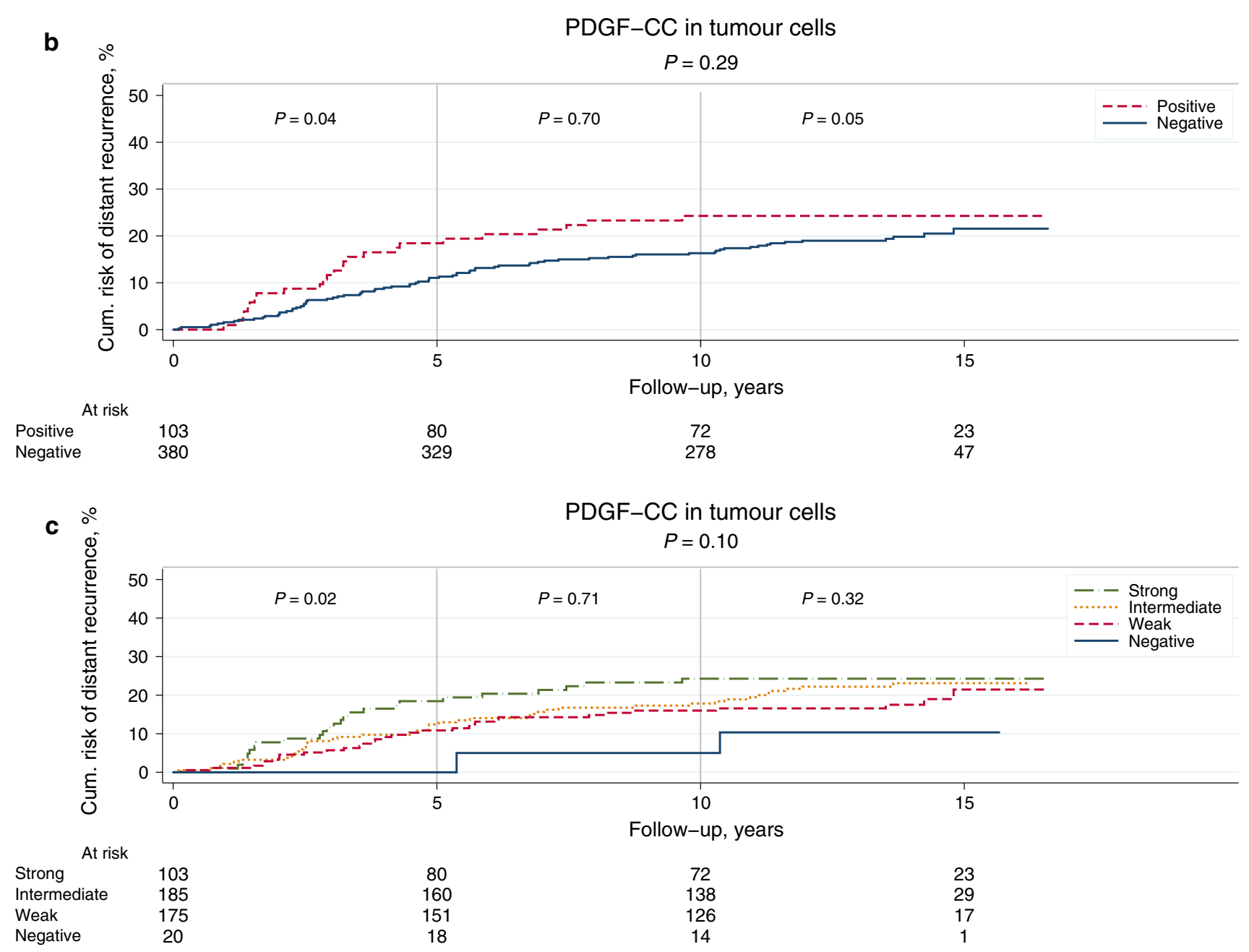

Fig. 4 a-c Kaplan-Meier survival curves showing DRFi (years) in relation to St Gallen molecular subtypes (a), expression of PDGF$\mathrm{CC}$ in tumour cells dichotomized into positive versus negative (b), and staining intensity of PDGF-CC ranging from 0 (negative) to 3 (strong) (c). $P$ values from log rank test and log rank linear trends for factor levels 
positive for PDGF-CC [Fig. 4b, HR 1.77 (95\% confidence interval (CI) 1.03-3.04), $P=0.04]$. This increase did not remain significant in multivariable analysis adjusted for age, tumour size, node status, NHG and St Gallen molecular subtype (HR 1.14; 95\% CI 0.59-2.19) (Supplementary Table S3). For the late events (occurring after 10 years), there was an increased risk amongst patients with tumours negative for PDGF-CC.

We also analysed the intensity of PDGF-CC expression $(0-3)$ and found a trend towards a worse prognosis with increasing expression of PDGF-CC over the whole time interval and a significantly worse prognosis during the first 5 years (Fig. 4c, log rank linear trends for factor levels $P=0.1$ and $P=0.02$, respectively).

Analysis of DRFi in relation to PDGF-receptor expression showed no difference in prognosis for patients with tumours positive versus negative for PDGFR $\alpha$ or PDGFR $\beta$ over the whole follow-up period (Supplementary Fig. S2a-c).

\section{Discussion}

We present novel data on expression of PDGFR $\alpha$, PDGFR $\beta$ and ligand PDGF-CC in primary breast tumours, synchronous lymph node metastasis and asynchronous recurrences in relation to St Gallen Molecular subtypes and long-term follow-up data in a large cohort of primary breast cancer patients. Data are accumulating on the importance of the PDGF receptors $\alpha$ and $\beta$ in breast cancer, but the presented results have been conflicting and not related to modern pathology. Furthermore, little is known concerning the role of ligand PDGF-CC. We found that high expression of the investigated members of the PDGF family correlated to several prognostic patient and tumour characteristics that indicate tumours' inherent biological aggressiveness (e.g. younger age, increasing NHG, high Ki67 and negative ER and PR). This is in line with what has been reported in some previous studies $[9,10]$ but it contrasts with Weigel et al. who found no significant correlations between PDGFR and the expression of established prognostic biomarkers. Reasons for diverging data could be the use of different antibodies, different inclusion criteria and the location of marker expression.

Interestingly, we report for the first time a significant upregulation of tumour cell PDGFR $\alpha$ expression in lymph node metastasis and asynchronous recurrences, as a sign of its role in tumour progression. Moreover, we found a significantly increased risk of early breast cancer recurrence amongst patients with tumours expressing increasing levels of PDGFCC. This effect was visualised by the Kaplan-Meier survival curves which indicate that the prognosis is related to the level of PDGF-CC expression (Fig. 4c). Up-regulation of members of the PDGF signalling pathway has previously been shown to occur during epithelial-to-mesenchymal transition in in vitro/in vivo cellular models [22], and subsequent experiments in mouse tumour models present support that an autocrine PDGF/PDGFR loop contribute to tumour progression and metastasis in vivo [23]. These studies conclude that PDGFR signalling plays an essential role during cancer progression, as has also been observed in our findings.

Approximately $30 \%$ of women with primary breast cancer eventually experience distant breast cancer recurrence. We found that high expression of PDGFR $\alpha$ in tumour cells of the primary tumour was correlated to subsequent first distant recurrence occurring within CNS. Even if prognosis in metastatic breast cancer has improved over the past decades [24], metastasis within CNS is a major limitation of life quality and survival [25]. Deciphering the biology behind metastasis and target organs for metastatic spread is important in order to develop targeted therapies. In glioblastoma, autocrine signalling by PDGF-CC/PDGFR $\alpha$ has been proposed to have a role in tumour development and Lokker et al. detected concomitant expression of PDGF$\mathrm{CC}$ and PDGFR $\alpha$ in 6/6 tested glioblastoma cell lines, and $5 / 5$ investigated primary glioblastoma tissue samples [26]. Furthermore, PDGF-CC has been shown to increase the permeability of the blood-brain barrier (BBB) [27], and the role of the PDGFR $\alpha /$ PDGF-CC pathway relative to BBB dysfunction in neurological disorders was recently reviewed [28]. In our cohort, patients who developed CNS metastases had primary tumours with high expression of tumour cell PDGFR $\alpha$ in 67\%, PDGF-CC in 50\% and concomitant high ligand/receptor expression in $33 \%$ of cases, indicating an active role of the PDGF pathway in these tumours. Thus it is possible that the PDGF pathway is involved when a tumour cell crosses the BBB. The number of patients with CNS recurrence is small within this cohort but the finding is intriguing. Unfortunately, we had no tumour tissue available from CNS metastases to explore the expression of the PDGF members. However, Kim et al. recently investigated the expression of tumour cell PDGFR $\alpha$ in breast cancer CNS metastases and found high expression in 12/38 (32\%) metastases [29]. Unfortunately, comparisons between these different studies are limited due to different antibodies and scoring systems for PDGFR $\alpha$ staining.

In this study we also explored concomitant expression of PDGFR $\alpha$ and PDGFR $\beta$, and ligand PDGF-CC. Experiments in vitro have shown that PDGF-CC binds to and stimulates homodimers of PDGFR $\alpha$, and heterodimers of PDGFR $\alpha$ and PDGFR $\beta$, but not homodimers of PDGFR $\beta$ [30]. However, the binding capacity of PDGF-CC in vivo is not completely known and we thus explored all the three receptor/ligand combinations. Almost all tumours with high stromal cell PDGFR $\beta$ and high tumour cell PDGF$\mathrm{CC}$ also had high PDGFR $\alpha$, either in stromal or tumour cells. In contrast, more than half of the tumours with high 
PDGF-CC and high PDGFR $\alpha$ expression in tumour or stromal cells displayed low PDGFR $\beta$. These findings support that PDGF-CC binds to and signals though receptor combinations including the PDGFR $\alpha$ in vivo. Concomitant PDGFR $\alpha$ and PDGF-CC expression varied markedly over the molecular subtypes where the TNBC displayed co-expression in $59 \%$ of the tumours, whereas the luminal subtypes only displayed co-expression in 5\% (Luminal A) to $19 \%$ (Luminal B HER2+). This adds further evidence to the involvement of the PDGF signalling pathway in TNBC as indicated in previous studies $[8,9,13]$ and this pathway might thus be a target for therapy in this difficult-to-treat subgroup of breast cancer.

The strength of the present study is that it is performed in a large cohort of breast cancer patients with long followup time (13.7 years). The study enables analysis of the PDGF signalling pathway in tumour tissue biopsies from several locations where data on clinically important biomarkers and St Gallen molecular subtypes were available, which allows to evaluate the study results in relation to modern pathology. A limitation is that there was limited tissue material available from lymph node metastasis and recurrences. Also, we recorded distant recurrence and/or breast cancer-related death in only $20 \%$ of patients during the follow-up time diminishing the power of the study.

In conclusion, we show that high expression of PDGFR $\alpha, \operatorname{PDGFR} \beta$ and ligand PDGF-CC is associated to several important prognostic patient and tumour characteristics in breast cancer, indicating a link to tumours with inherent biological aggressiveness. Tumour cell expression of PDGFR $\alpha$ is commonly up-regulated in lymph node metastases and asynchronous recurrences, whereas high expression of PDGF-CC is related to early breast cancer recurrence supporting an active role of the PDGF signalling pathway in tumour progression. Furthermore, our results indicate an intriguing connection between the PDGF pathway and metastatic spread to the CNS, which merits further exploration. In summary, our data encourage further evaluation of the PDGF receptors and ligands in breast cancer, as well as of strategies to target this pathway since evidence is compiling for its involvement in breast cancer progression.

Acknowledgements This paper was supported by funds from the Swedish Breast Cancer Organization (BRO), The Swedish Cancer Society, The Gunnar Nilsson Cancer Foundation, The Mrs Berta Kamprad Foundation, Skåne County Council's Research and Development Foundation, Governmental Funding of Clinical Research within the National Health Service (ALF), The Gyllenstiernska Krapperup Foundation and ERC Consolidator Grant. We would like to thank Kristina Lövgren for immunohistochemical staining and late Dr. Dorthe Aamand Grabau, clinical pathologist, for immunohistochemical assessments. We also would like to thank Professor Ulf Eriksson and Professor Andrew M Scott for providing the PDGF-CC antibody.

\section{Compliance with ethical standards}

Conflict of interest The authors declare that they have no conflict of interest.

Open Access This article is distributed under the terms of the Creative Commons Attribution 4.0 International License (http://creativeco mmons.org/licenses/by/4.0/), which permits unrestricted use, distribution, and reproduction in any medium, provided you give appropriate credit to the original author(s) and the source, provide a link to the Creative Commons license, and indicate if changes were made.

\section{References}

1. Demoulin JB, Essaghir A (2014) PDGF receptor signaling networks in normal and cancer cells. Cytokine Growth Factor Rev 25(3):273-283. https://doi.org/10.1016/j.cytogfr.2014.03.003

2. Nazarenko I, Hede SM, He X, Hedren A, Thompson J, Lindstrom MS, Nister M (2012) PDGF and PDGF receptors in glioma. Upsala J Med Sci 117(2):99-112. https://doi.org/10.3109/03009 734.2012.665097

3. Heinrich MC, Corless CL, Duensing A, McGreevey L, Chen CJ, Joseph N, Singer S, Griffith DJ, Haley A, Town A, Demetri GD, Fletcher CD, Fletcher JA (2003) PDGFRA activating mutations in gastrointestinal stromal tumors. Science 299(5607):708-710. https://doi.org/10.1126/science.1079666

4. Golub TR, Barker GF, Lovett M, Gilliland DG (1994) Fusion of PDGF receptor beta to a novel ets-like gene, tel, in chronic myelomonocytic leukemia with $\mathrm{t}(5 ; 12)$ chromosomal translocation. Cell 77(2):307-316

5. Ehnman M, Ostman A (2014) Therapeutic targeting of plateletderived growth factor receptors in solid tumors. Expert Opin Investig Drugs 23(2):211-226. https://doi.org/10.1517/13543 784.2014.847086

6. Andrae J, Gallini R, Betsholtz C (2008) Role of plateletderived growth factors in physiology and medicine. Genes Dev 22(10):1276-1312. https://doi.org/10.1101/gad.1653708

7. Carvalho I, Milanezi F, Martins A, Reis RM, Schmitt F (2005) Overexpression of platelet-derived growth factor receptor alpha in breast cancer is associated with tumour progression. Breast Cancer Res 7(5):R788-R795. https://doi.org/10.1186/bcr1304

8. Jansson S, Bendahl PO, Grabau DA, Falck AK, Ferno M, Aaltonen K, Ryden L (2014) The three receptor tyrosine kinases c-KIT, VEGFR2 and PDGFRalpha, closely spaced at 4q12, show increased protein expression in triple-negative breast cancer. PLoS One 9(7):e102176. https://doi.org/10.1371/journal.pone.0102176

9. Park SY, Kim HM, Koo JS (2015) Differential expression of cancer-associated fibroblast-related proteins according to molecular subtype and stromal histology in breast cancer. Breast Cancer Res Treat 149(3):727-741. https://doi.org/10.1007/s 1054 9-015-3291-9

10. Paulsson J, Sjoblom T, Micke P, Ponten F, Landberg G, Heldin CH, Bergh J, Brennan DJ, Jirstrom K, Ostman A (2009) Prognostic significance of stromal platelet-derived growth factor beta-receptor expression in human breast cancer. Am J Pathol 175(1):334-341. https://doi.org/10.2353/ajpath.2009.081030

11. Anderberg C, Li H, Fredriksson L, Andrae J, Betsholtz C, Li X, Eriksson U, Pietras K (2009) Paracrine signaling by plateletderived growth factor-CC promotes tumor growth by recruitment of cancer-associated fibroblasts. Can Res 69(1):369-378. https:// doi.org/10.1158/0008-5472.can-08-2724 
12. Pietras K, Pahler J, Bergers G, Hanahan D (2008) Functions of paracrine PDGF signaling in the proangiogenic tumor stroma revealed by pharmacological targeting. PLoS Med 5(1):e19. https ://doi.org/10.1371/journal.pmed.0050019

13. Roswall P, Bocci M, Bartoschek M, Li H, Kristiansen G, Jansson S, Lehn S, Sjölund J, Reid S, Larsson C, Eriksson P, Anderberg C, Cortez E, Saal LH, Orsmark-Pietras C, Cordero E, Kristian Haller B, Häkkinen J, Burvenich IJG, Lim E, Orimo A, Höglund M, Rydén L, Moch H, Scott AM, Eriksson U, Pietras K (2018) Microenvironmental control of breast cancer subtype elicited by paracrine platelet derived growth factor-CC signaling. Nat Med (in press)

14. Perou CM, Sorlie T, Eisen MB, van de Rijn M, Jeffrey SS, Rees CA, Pollack JR, Ross DT, Johnsen H, Akslen LA, Fluge O, Pergamenschikov A, Williams C, Zhu SX, Lonning PE, BorresenDale AL, Brown PO, Botstein D (2000) Molecular portraits of human breast tumours. Nature 406(6797):747-752. https://doi. org $/ 10.1038 / 35021093$

15. Goldhirsch A, Winer EP, Coates AS, Gelber RD, Piccart-Gebhart M, Thurlimann B, Senn HJ (2013) Personalizing the treatment of women with early breast cancer: highlights of the St Gallen International Expert Consensus on the Primary Therapy of Early Breast Cancer 2013. Ann Oncol 24(9):2206-2223. https://doi. org/10.1093/annonc/mdt303

16. Foulkes WD, Smith IE, Reis-Filho JS (2010) Triple-negative breast cancer. N Engl J Med 363(20):1938-1948. https://doi. org/10.1056/NEJMra1001389

17. Mayer IA, Abramson VG, Lehmann BD, Pietenpol JA (2014) New strategies for triple-negative breast cancer-deciphering the heterogeneity. Clin Cancer Res 20(4):782-790. https://doi. org/10.1158/1078-0432.CCR-13-0583

18. Falck AK, Bendahl PO, Ingvar C, Isola J, Jonsson PE, Lindblom P, Lovgren K, Rennstam K, Ferno M, Ryden L (2012) Analysis of and prognostic information from disseminated tumour cells in bone marrow in primary breast cancer: a prospective observational study. BMC Cancer 12(1):403. https://doi. org/10.1186/1471-2407-12-403

19. Falck AK, Bendahl PO, Chebil G, Olsson H, Ferno M, Ryden L (2013) Biomarker expression and St Gallen molecular subtype classification in primary tumours, synchronous lymph node metastases and asynchronous relapses in primary breast cancer patients with 10 years' follow-up. Breast Cancer Res Treat 140(1):93-104. https://doi.org/10.1007/s10549-013-2617-8

20. Falck AK, Rome A, Ferno M, Olsson H, Chebil G, Bendahl PO, Ryden L (2016) St Gallen molecular subtypes in screeningdetected and symptomatic breast cancer in a prospective cohort with long-term follow-up. Br J Surg 103(5):513-523. https://doi. org/10.1002/bjs. 10070
21. McShane LM, Altman DG, Sauerbrei W, Taube SE, Gion M, Clark GM (2006) REporting recommendations for tumor MARKer prognostic studies (REMARK). Breast Cancer Res Treat 100(2):229-235. https://doi.org/10.1007/s10549-006-9242-8

22. Jechlinger M, Grunert $\mathrm{S}$, Tamir IH, Janda E, Ludemann S, Waerner T, Seither P, Weith A, Beug H, Kraut N (2003) Expression profiling of epithelial plasticity in tumor progression. Oncogene 22(46):7155-7169. https://doi.org/10.1038/sj.onc.1206887

23. Jechlinger M, Sommer A, Moriggl R, Seither P, Kraut N, Capodiecci P, Donovan M, Cordon-Cardo C, Beug H, Grunert S (2006) Autocrine PDGFR signaling promotes mammary cancer metastasis. J Clin Investig 116(6):1561-1570. https://doi.org/10.1172/ jci24652

24. Sundquist M, Brudin L, Tejler G (2017) Improved survival in metastatic breast cancer 1985-2016. Breast 31:46-50. https://doi. org/10.1016/j.breast.2016.10.005

25. Witzel I, Oliveira-Ferrer L, Pantel K, Muller V, Wikman H (2016) Breast cancer brain metastases: biology and new clinical perspectives. Breast Cancer Res 18(1):8. https://doi.org/10.1186/s1305 8-015-0665-1

26. Lokker NA, Sullivan CM, Hollenbach SJ, Israel MA, Giese NA (2002) Platelet-derived growth factor (PDGF) autocrine signaling regulates survival and mitogenic pathways in glioblastoma cells: evidence that the novel PDGF-C and PDGF-D ligands may play a role in the development of brain tumors. Can Res 62(13):3729-3735

27. Su EJ, Fredriksson L, Geyer M, Folestad E, Cale J, Andrae J, Gao Y, Pietras K, Mann K, Yepes M, Strickland DK, Betsholtz C, Eriksson U, Lawrence DA (2008) Activation of PDGF-CC by tissue plasminogen activator impairs blood-brain barrier integrity during ischemic stroke. Nat Med 14(7):731-737. https://doi. org $/ 10.1038 / \mathrm{nm} 1787$

28. Lewandowski SA, Fredriksson L, Lawrence DA, Eriksson U (2016) Pharmacological targeting of the PDGF-CC signaling pathway for blood-brain barrier restoration in neurological disorders. Pharmacol Ther 167:108-119. https://doi.org/10.1016/j. pharmthera.2016.07.016

29. Kim HM, Jung WH, Koo JS (2015) Expression of cancer-associated fibroblast related proteins in metastatic breast cancer: an immunohistochemical analysis. J Transl Med 13:222. https://doi. org/10.1186/s12967-015-0587-9

30. Gilbertson DG, Duff ME, West JW, Kelly JD, Sheppard PO, Hofstrand PD, Gao Z, Shoemaker K, Bukowski TR, Moore M, Feldhaus AL, Humes JM, Palmer TE, Hart CE (2001) Platelet-derived growth factor C (PDGF-C), a novel growth factor that binds to PDGF alpha and beta receptor. J Biol Chem 276(29):2740627414. https://doi.org/10.1074/jbc.M101056200 